\title{
THE MANAGEMENT OF SICKNESS ABSENCE
}

Stuart C Whitaker

S ickness absence, or as it can be defined more precisely, absence from work that is attributed to sickness by the employee and accepted as such by the employer, remains high on the agenda for governments in the European Union (EU). Over the last decade most EU governments have implemented legislation that changes social security payments for the initial period of sickness absence. ${ }^{1}$ This has had the effect of transferring the initial cost of sickness absence away from the taxpayer to the employer, who it is thought will have more direct control over absence from work. In some countries the cost of the initial period of sickness absence has also been transferred back to the employee by, for example, removing payment for the first day or two of any new period of sickness absence, reducing the level of sickness benefit paid, and in some circumstances by changing the employment status of some groups of employees from direct employees to self employed status, where they are responsible for their own sickness absence and other labour costs.

In addition many EU governments have introduced programmes aimed at encouraging long term absentees back into work and making more stringent the medical standards required for early retirement on the grounds of ill health. In Denmark, for example, the government introduced a programme called "social engagement of companies" aimed at improving the situation for long term absentees and reducing exclusion from the workplace. In Norway the government and the social partners agreed a national campaign to reduce absenteeism. ${ }^{2}$ In the Netherlands, in 1994, the Dutch government passed legislation that requires employers to engage certified occupational health services in order to help them manage sickness absence better. ${ }^{\mathrm{w} 1}{ }^{\mathrm{w} 2}$ In the UK the government has taken additional steps to try to reduce absence from work by, for example, setting targets to reduce sickness absence in public sector workers by $30 \%{ }^{3}$ and by integrating targets for reducing sickness absence by $30 \%$ as part of a public health agenda. ${ }^{\text {w3 }}$

\section{COSTS OF ABSENCE}

Whoever pays for the cost of sickness absence, it is well recognised that the costs are enormous. As well as the salary costs for the person who is absent there are the costs of replacement staff or overmanning of the organisation to take account of a specific level of absence, costs associated with lost productivity, or reduced quality of services, as well as the management, human resources, and occupational health time spent dealing with absence that could be used for other purposes. In order to give some idea of the scale of the problem several examples are given in box 1 .

Correspondence to: Dr S Whitaker, Institute of Occupational Health, University of Birmingham, Birmingham B15 2TT, UK

s.c.whitaker@bham.ac.uk

\section{Box 1: Cost of sickness absence-the scale of the problem}

In the UK 177 million working days were lost in 1994. This has been assessed at over $£ 11$ billion (13.2 billion ECU)

- In Portugal, the two thousand largest enterprises lost 7731 million working days as a result of illness and 1665 million working days due to accidents in 1993

- In the Netherlands, the absence rate was $8.3 \%$ in 1993, and $14.2 \%$ of the workforce were registered as disabled. The cost of providing benefits was NLG35 billion (16.6 billion ECU, 4.1 billion ECU on sickness absence and 12.5 billion ECU on disability benefits)

- In Germany employers paid up to DM60 billion (30.5 billion ECU) for social security insurance to cover costs of absence from work in 1993

- In Belgium, with an absence rate of about 7\%, BFr93 billion (2.4 billion ECU) was paid on sickness benefits in 1995 and BFr21 billion (0.6 billion ECU) for benefits on accidents and occupational diseases

Preventing absenteeism at the workplace

European Foundation ${ }^{2}$ 


\section{Comparing levels of absence}

Comparing sickness absence rates between countries, and sometimes between different organisations within the same country, can be complicated because of the use of different definitions of absence, variation in the criteria for inclusion and exclusion, and differences in the populations being compared and in the accuracy of the sickness absence data collected. For example, within the EU, some countries exclude groups such as all public sector or self employed workers from the national figures. Others include those on permanent disability benefits or maternity leave in the sickness absence figures, and at least one can not separate absence due to illness from other reasons for absence. The European Foundation investigated sickness absence within the EU and did not publish a league table of absence rates between countries because of the risk of presenting misleading information. At best we can say that we do not have accurate, reliable sickness absence figures that are capable of direct comparison within the EU. ${ }^{2}$ Policy makers and politicians therefore need to be cautious in their interpretation of the absence figures that are available both at the national and international level.

Even within the same country sickness absence can be defined differently by different organisations. In some a month's sickness absence is recorded as four calendar weeks (28 days), while in others it is four working weeks (20 days). Some organisations capture information on partial shift absences, hospital or dental appointments, while others do not. The denominator used to calculate the absence rate can also vary. Some organisations use contracted hours and others use established hours (which includes contracted hours for positions that are vacant, but budgeted for), and some make an adjustment for annual leave, largely as a result of whether the information is being collected for payroll or for manpower planning purposes. The hours lost due to maternity leave are often not recorded as sickness absence in the UK; however, the contracted hours for those on maternity leave are often still included in the denominator and this could have a significant effect when calculating the rate in working populations where there is a high female population. How employees, who still have an employment contract but have run out of statutory sick pay, are dealt with in calculating the absence rate can also vary between organisations.

The absence rate is often reported based on the average (mean) figure, but in some circumstances, because of the binomial distribution of absence data, some use the median figure to report the absence rate. All of the above can be further complicated by variation in the reliability of the systems used by different organisations to capture and record absence data.

Perhaps the most common way of determining the rate of absence in the UK is: lost hours over contracted hours, without any adjustment for annual leave, excluding maternity leave from the numerator and discounting partial shift absences, hospital appointments, etc. The rate is most often reported as an average (mean) rate of absence.

The overall rate of absence gives no indication of the pattern of absence that predominates in an organisation. A large number of frequent, short term absences or a small number of long term absences can result in the same figure. The overall rate of absence is too crude a measure to be used on its own to indicate whether interventions to reduce absence are working effectively or not.

Some have reported the medical reasons for absence in defined populations. ${ }^{\text {w4-6 }}$ These studies often use different classification systems as there is no one standardised approach to classifying the reasons for absence that is widely used. The thorny problem that has not been resolved as yet is how to determine what percentage of sickness absence is directly attributable to conditions that have been caused or made worse by work.

\section{Managing attendance}

Managing attendance at work is always a line management responsibility. Most guidance documents on managing attendance stress the importance of having a robust attendance/absence management policy that defines clearly, for managers and staff, what sickness absence is, when it can be taken, how and when it should be reported and recorded, and what steps should be taken to manage attendance at an individual level. This often starts with having a well maintained individual attendance (or absence) record that captures information on the frequency and duration of spells of absence over a period of time, often one year. The individual record may also allow periods of absence to be linked to days of the week when sickness absence is taken, or to other events, such as holidays or weekends in order to identify possible trends in the pattern of absence. However, little attention has been paid to relating patterns of absence to changing working conditions, types of exposure or organisational events, such as downsizing, although all of these factors have been linked to increased absence.

The importance of carrying out individual return to work interviews for employees who have been absent is often stressed. It is suggested that the return to work interview signals to the employee that absence is taken seriously in the organisation, and it offers the manager and the employee the opportunity to discuss, in an informal setting, any issues that may be affecting attendance or performance at work. Some organisations set triggers for further action, such as automatic management review if the employee has been absent for more than three episodes in a 12 month period, or automatic referral to the occupational health service after a specific number of spells or specific duration of absence.

\section{Referral to occupational health}

When the manager makes a formal referral for the employee to be seen by the occupational health service because of their sickness absence there is often a strong element of compulsion for the employee to attend. Refusal may lead to negative consequences for the employee. However, management and staff may not appreciate fully that an employee cannot be compelled to undergo any form of medical examination or health assessment without first having given their informed consent for that assessment to take place. Consent can only be regarded as informed when the individual understands what information is being released, to whom, the purposes for which it will be used, and the possible consequences of that use. Consent must be given freely, under no duress or threat, and applies only for the time and event for which it is given. ${ }^{\mathrm{w} 7}$ Therefore the employee has a legitimate right to refuse a medical examination. However, they should understand that refusal to undergo a medical examination does not preclude further management action from being taken.

Questions that are frequently posed by managers to occupational health professionals on sickness absence referral letters are listed in box 2 . 
Box 2: Questions frequently asked by managers to occupational health professionals on referral

- Can you confirm that there is an underlying medical condition causing the current level of absence?

- Can you estimate the length of time the employee is likely to be absent from work with this condition?

- Can you indicate whether, on return to work, the employee is likely to be able to resume his or her normal duties?

- Are there likely to be any implications for the health and safety of the employee or others on his or her return to work?

- Should restricted duties, redeployment or retirement on the grounds of ill health be considered at this stage?

- Does disability discrimination legislation apply in this case?

\section{Verifying the reason for absence}

It is often the first question in box 2 that causes the most concern. The occupational health professional is being asked to verify the reason for absence and to say whether, in their opinion, the length or pattern of absence, often certified by the general practitioner, is justified. If they indicate that, in their opinion, it is not, this calls into question the genuineness of the illness, and the employee's honesty or commitment to the organisation, and may lead to the manager pursuing disciplinary action against the employee. Under these circumstances the employee may feel that their role, during the health assessment, is to convince the occupational health professional that their absence can be justified on medical grounds. This may lead to employees wanting to present their case in the best possible light, exaggerating their symptoms and being unwilling to enter into any open discussion on other, strictly non-medical factors, that may nevertheless play a significant part in their absence from work.

There is concern that placing the doctor or nurse in the position of having to verify the reason for absence on behalf of the employer so changes the nature of the doctor-patient, nurse-patient relationship that this activity raises serious ethical questions. The International Labour Organisation, a tripartite organisation of the social partners, has published technical and ethical guidance which states that "Occupational health professionals should not be required by the employer to verify the reasons for absence from work". ${ }^{4}$ This is largely in order to protect the relationship of trust that is essential for open and honest communication between a patient and health care professional.

In Holland general practitioners have refused to certify the reason for absence from work since the beginning of the 20 th century in order to protect the confidential relationship with their patients'. ${ }^{\text {2 }}$ At one point the British Medical Association also pressed for the same position. ${ }^{5}$ Since 1994 Dutch occupational physicians, despite fierce protests, have been forced to undertake the task of certification. ${ }^{\text {w2 }}$ Recent research suggests that Dutch general practitioners do not trust occupational physicians who undertake this task on behalf of employers. ${ }^{\text {w8 }}$ In Germany it is not only considered unethical for the occupational physician to be asked to verify the reason for absence but also legislation prevents them from doing so. In Spain occupational physicians threatened to take industrial action if they were to be required to verify the reasons for absence. Yet in the UK this question has become widely accepted without causing any further debate on the role of the occupational physician in verifying the reason for absence or on how this activity might affect the relationship between occupational health services and workers. Whether the UK is leading the field in this respect or adopting practices that other health care professionals are unwilling to accept needs further consideration.

\section{The complex phenomenon of sickness absence}

Sickness absence is a complex phenomenon that is influenced strongly by factors other than health. The decision to attend or resume work following sickness absence will be related to the real and perceived conditions of work (both physical and psychosocial), anticipated job demands, management attitudes and behaviours, social norms in the peer group and community, advice and information from general practitioners and hospital specialists, as well as economic pressures caused through loss of earnings (for the individual) and loss of productivity (for the organisation). There are also other factors that operate at the individual level, such as the person's health beliefs, sickness behaviour, motivation to attend, and job satisfaction that play a part in this decision making process. It has been suggested that many workers will attend work with conditions that others will be absent with, ${ }^{5}$ and that where there are high rates of absence there are also high rates of "presenteeism". ${ }^{\mathrm{w} 9}$

If occupational health professionals are to develop interventions that are effective in helping people to return to work and remain at work, they will need to develop a good understanding of the factors other than disease that influence this behaviour. They will need to find new ways of working with organisations to identify and implement strategies aimed at reducing absence that take account of these factors. This will require close cooperation between line managers, human resources, worker representatives, and occupational health professionals.

It is likely that these strategies, which take account of the broad range of factors that affect sickness absence, will become increasingly important in the future as government policy will require more long term absentees to be reintegrated back into the workforce to prevent social exclusion; fewer people with health problems may be allowed to retire on health grounds, and at the same time there will be increasing pressure placed on employers to reduce sickness absence still further. New and more dynamic approaches to sickness absence may need to be developed.

Sickness absence can be viewed from a number of different perspectives, and these are listed in box 3 . However it is rare that these sometimes conflicting perspectives can be reconciled and all of the different factors that affect sickness absence can be considered together. The factors that have been linked to increased rates of absence are shown in box 4 .

These factors have been investigated by a number of different disciplines. Social scientists have viewed sickness absence as a phenomenon that arises out of a set of written and unwritten rules that operate within the context of the labour market in a capitalist society. ${ }^{\text {w10 }}$ They have concentrated on the influence that sickness absence benefits and social insurance systems can have on paid absence from work. ${ }^{6}$ The impact of severe economic decline, ${ }^{7}$ industrial downsizing, ${ }^{\mathrm{w} 11}$ socioeconomic differences, ${ }^{8}$ w12 and other factors such as sex, ${ }^{9}$ w13-17 ethnic group, ${ }^{\text {w18 }}$ and regional variation ${ }^{\mathrm{w} 10}$ have been described.

Psychologists have investigated individual factors such as personality, job stress, performance and absenteeism, ${ }^{10}$ job satisfaction, ${ }^{\mathrm{w} 19 \mathrm{w} 20}$ and the relation between short and long term sickness with social circumstances, working conditions, and 


\section{Box 3: Different perspectives on sickness absence}

From the social perspective in terms of the rights and benefits that society considers should be made available to those who are unable to work because of illness

- From the economic perspective, including the impact that sickness absence has on productivity and sustainable development at the national and local level

- From the perspective of line managers and human resources who have to manage individuals and groups of workers within the framework of employment law

From the perspective of health care professionals involved in helping to protect the health of workers

From the perspective of employees and trades unions

\begin{tabular}{|c|c|c|}
\hline Macro level & Organisational level & Individual level \\
\hline $\begin{array}{l}\text { - climate } \\
\text { - epidemics } \\
\text { - provision of health care } \\
\text { services } \\
\text { - social insurance systems } \\
\text { - sickness certification } \\
\text { practices } \\
\text { - taxation } \\
\text { - pensionable age } \\
\text { - social attitudes } \\
\text { - economic climate } \\
\text { - availability of alternative } \\
\text { employment } \\
\text { - unemployment }\end{array}$ & $\begin{array}{l}\text { - the nature of the } \\
\text { industry } \\
\text { - working conditions } \\
\text { - job demands } \\
\text { - size of the enterprise } \\
\text { characteristics of the } \\
\text { workforce } \\
\text { - indusorce availability } \\
\text { - supervial relations } \\
\text { - personnel policies } \\
\text { - labour turnover } \\
\text { - the provision of } \\
\text { occupational health } \\
\text { services }\end{array}$ & $\begin{array}{l}\text { - age } \\
\text { - sex } \\
\text { - occupational status } \\
\text { - job satisfaction } \\
\text { - length of service } \\
\text { - personality } \\
\text { - life crises } \\
\text { ramily } \\
\text { responsibilities } \\
\text { - locial support } \\
\text { - alcoho activities } \\
\text { - the health status of } \\
\text { the individual }\end{array}$ \\
\hline
\end{tabular}

sex. ${ }^{11}$ In addition the influence of psychosocial factors, ${ }^{12-14}$ w21 social support, ${ }^{15}{ }^{16}$ marital status, ${ }^{\mathrm{w} 22}$ stress, ${ }^{\mathrm{w} 23}$ and psychiatric morbidity ${ }^{\mathrm{w} 24-30}$ have been considered.

From an organisational perspective factors such as personal and organisational determinants of perceived absence norms, ${ }^{\mathrm{w} 31}$ changes in the psychosocial work environment, ${ }^{14}$ organisational change, ${ }^{\mathrm{w} 32}$ relationship between job insecurity and work based support, ${ }^{\mathrm{w} 33}$ positive peer group interaction at work, and satisfaction with co-workers ${ }^{\text {w22 }}$ have been investigated.

Health professionals have investigated the impact on sickness absence of occupational health services, ${ }^{17}$ w34 health promotion $^{\mathrm{w} 35-38}$ employee fitness programmes, ${ }^{\mathrm{w} 39}{ }^{\mathrm{w} 40}$ physiotherapy services, ${ }^{\mathrm{w} 41}{ }^{\mathrm{w} 42}$ vaccination programmes ${ }^{\mathrm{w} 43}$ as well as the effect of work load. ${ }^{18}$

\section{Conclusions}

Sickness absence is likely to remain high on the agenda for government and industry. Occupational health professionals need to have a broad understanding of the factors, other than disease, that affect sickness absence if they are to be able to advise organisations, communicate effectively with line managers, and work with individuals. However, the role of the occupational health service in relation to sickness absence must be defined clearly and communicated to staff and management if they are to avoid being used simply as a management tool. A positive approach to tackling absence, including the non-medical, psychosocial issues that have been shown to have such an important influence on absence, should be developed further. This will require close
Box 5: Management of sickness absence-key points

Sickness absence remains high of the agenda for governments in Europe

v The financial cost of sickness absence in EU member states remains enormous

- Most EU member states have implemented legislation that requires employers, and in some circumstances employees, to bear the initial costs of sickness absence

- Increasingly employers are turning to occupational health services to help them manage attendance better

- New methods of working with organisations, that recognises that ill health is only one factor to consider in managing sickness absence, are required

Sickness absence is affected by a large number of different factors:

- social insurance systems, benefits payments, and medical certification practices influence attendance at work

- job security, availability of alternative employment, and economic climate affect attendance

- organisational factors such as size of the enterprise, personnel policies, and management procedures affect attendance

- job satisfaction, workplace stress, and psychosocial work environment affect attendance

- individual factors, such as personality, social support, marital status and ill health affect attendance

cooperation with human resources, line management, and workers representatives. The management approach to sickness absence that has largely been adopted in industrialised countries ${ }^{19}$ provides an important framework for managing attendance, but new and innovative approaches to help organisations overcome barriers to attendance need to be developed further. The concept that sickness absence can have positive benefits should also be recognised as sickness absence has been considered to be too low in some circumstances. ${ }^{20}$ Occupational health professionals are well placed to promote a positive approach to dealing with sickness absence, both at an organisational and individual level.

website extra

Additional references appear on the Occupational and Environmental Medicine website

www.occenvmed.com

\section{References}

1 Grundemann RWM, Vuuren CV. Preventing absenteeism at the workplace: European research report. European Foundation for the Improvement of Living and Working Conditions, Office for Official Publications of the European Communities, Luxembourg, 1997.

- This and the report in reference 2 present the results of a European wide project to identify and discuss strategies to reduce absence.

2 Grundemann RWM, Vuuren CV. Preventing absenteeism at the workplace: a European portfolio of case studies. European Foundation for the Improvement of Living and Working Conditions, Office for Official Publications of the European Communities, Luxembourg, 1998.

3 Cabinet Office. Managing attendance in the public sector: putting best practice to work. London: Central Office of Information, 1999.

This describes the "state of the art" in managing attendance from a management perspective 
4 International Labour Office. Technical and ethical guidelines for workers' health surveillance. Geneva: International Labour Office, 1998 (Occupational Safety and Health Series No. 72).

This article and the one below provide a useful insight into how sickness absence has been viewed from an occupational health perspective.

5 Taylor P. Sickness absence: facts and misconceptions. J R Coll Physicians 1974;8:315-33.

6 Alexanderson K. Sickness absence: a review of performed studies with focus on levels of exposures and theories utilized. Scand J Soc Med 1998;26:241-9.

7 Kivimaki M, Vahetra J, Thomson L, et al. Psychosocial factors predicting employee sickness absence during economic decline. $J$ Applied Psychol 1997;82:858-72.

8 North F, Syme SL, Feeney A, et al. Explaining socioeconomic differences in sickness absence: the Whitehall II study. BMJ 1993;306:361-6

9 Messing K, Tissot F, Saurel Cubizolles MJ, et al. Sex as a variable can be surrogate for some working conditions: factors associated with sickness absence. J Occup Environ Med 1998;40:250-60.

10 Arsenault A, Dolan S. The role of personality, occupation and organization in understanding the relationship between job stress, performance and absenteeism J Occup Psychol 1983;56:227-40.

11 Blank N, Diderichsen F. Short-term and long-term sick leave in Sweden: relationships with social circumstances, working conditions and gender. Scand J Soc Med 1995;23:265-72.

12 Niedhammer I, Bugel I, Goldberg M, et al. Psychosocial factors at work and sickness absence in the Gazel cohort: a prospective study. Occup Environ Med 1998;55;735-41.

13 North FM, Syme SL, Feeney A, et al. Psychosocial work environment and sickness absence among British civil servants: the Whitehall II study. Am J Public Health 1996;86:332-40.

14 Vahtera J, Kivimaki M, Pentti J, et al. Effect of change in the psychosocial work environment on sickness absence: a seven year follow up of initially healthy employees. J Epidemiol Community Health 2000;54:484-93.

15 Rael EG, Stansfeld SA, Shipley M, et al. Sickness absence in the Whitehall II study, London: the role of social support and material problems. J Epidemiol Community Health 1995;49:474-81.

16 Vahtera J, Uutela A, Pentti J. The effect of objective job demands on registered sickness absence spells; do personal, social and job-related resources act as moderators? Work and Stress 1996;10:286-308.

17 Hamers P, Kamphius P, VanPoppel J. Relationship between occupational health care and absenteeism. Occupational Medicine 1992;42:188-92.

18 Bourbonnais R, Vinet A, Meyer F, et al. Certified sick leave and work load. Br J Occup Med 1992;34:69-74.

19 Balcombe J, Strange N, Tate G. Wish you were here-How UK and Japanese-owned organisations manage attendance. London: The Industrial Society, 1993.

Another "state of the art" report on how to manage attendance from a management perspective.

20 Kristensen TS. Sickness absence and work strain among Danish slaughterhouse workers: an analysis of absence from work regarded as coping behaviour. Soc Sci Med 1991;32:15-27.

\section{QUESTIONS (See answers on page 410)}

For each question, indicate which answers are true and which are false.

(1) In order to compare sickness absence figures between organisations the following are essential:

(a) The same personnel policies and management procedures for sickness absence

(b) The same definition of sickness absence

(c) The same computerised sickness absence recording system

(d) Reliable sickness absence recording systems in the organisations

(e) A standardised method of analysis of the sickness absence data in the organisations

(f) A standardised coding system for the medical reasons for absence

(g) Comparable working populations

(2) Monitoring the overall rate of absence over time in an organisation:

(a) Indicates if a few people are taking long periods of absence

(b) Indicates if most people are taking frequent short term absence

(c) Indicates whether the trend in sickness absence is going up or down

(d) Does not indicate whether interventions to reduce absence are working or not

(e) Indicates common underlying reasons for absence

(3) Which of these factors has been linked to increased sickness absence:

(a) Poor working conditions

(b) High job demands

(c) Low job satisfaction

(d) Being male

(e) Lack of social support

(f) Smoking

(4) The UK government has set targets to reduce absence in the public sector by what per cent?

(a) By $10 \%$ by the year 2002

(b) By $30 \%$ by the year 2003

(c) By $40 \%$ by the year 2005

(d) By $25 \%$ by the year 2003

(e) By $25 \%$ by the year 2005 